\title{
Considerações sobre os Determinantes do Spread Bancário no Brasil
}

\section{Considerations about the Determinants of Banking Spread in Brazil}

Maria Juliana Zeilmann Fabris* Fernando Ferrari Filho* *

Resumo: $O$ artigo objetiva contribuir para a análise dos determinantes da margem líquida de juros do sistema bancário brasileiro. Para tanto, foram analisados alguns desenvolvimentos a partir do modelo teórico proposto por Thomas Ho e Anthony Saunders (1981), bem como se verificou se a implementação do Regime de Metas de Inflação e do Sistema de Informações de Crédito surtiram efeitos sobre a evolução dos spreads.

Palavras-chave: Economia brasileira. Spread bancário. Análise econométrica.

Abstract: The article aims to analyze the macroeconomic determinants of banking spread in Brazil. For this purpose, it analyzed some theoretical models proposed by Thomas Ho and Anthony Saunders, among others, as well as it developed an econometric analysis to show if the Inflation Targeting Regime and the Credit Information System affected the banking spread evolution.

Keywords: Brazilian economy. Banking spread. Econometric analysis.

JEL Classification: E4; E43; E44.

\section{1lntrodução}

Na década de 1980 e no início dos anos 1990, a insuficiência do crédito no Brasil era comumente atribuída ao ambiente econômico marcado tanto pela alta inflação quanto pela incerteza que inibiam o investimento e causavam o elevado patamar de juros. A partir de julho de 1994, a estabilidade monetária, assegurada com o Plano Real, trouxe a expectativa de aumento sustentado da relação entre o crédito bancário e o produto interno bruto (PIB), fornecendo

\footnotetext{
* $\quad$ Doutora em Economia pela Universidade Federal do Rio Grande do Sul (UFRGS). Analista do Banco Central do Brasil (BCB). As opiniões expressas neste trabalho são exclusivamente dos autores e não refletem, necessariamente, a visão do BCB. E-mail: juliana.fabris@bcb.gov.br

* $\quad$ Professor titular do Departamento de Econômia e Relações Internacionais da Universidade Federal do Rio Grande do Sul (UFRGS). Pesquisador do CNPq. E-mail: ferrari@ufrgs.br
} 
maior liquidez à economia, o que, todavia, não ocorreu nos dez anos seguintes à implantação do referido Plano.

Nos primeiros meses do novo padrão monetário, real, houve crescimento da relação crédito bancário/PIB, mas o diagnóstico de que pressões de demanda, causadas pelo fim do imposto inflacionário, poderiam ser perniciosas para a manutenção da estabilidade monetária levou à adoção de políticas monetárias restritivas, que reduziram as disponibilidades destinadas ao crédito bancário. Ademais, por um lado, quase que simultaneamente, o contágio da crise de balanço de pagamentos do México provocou forte elevação da taxa básica de juros no Brasil. Por outro lado, entre 1997 e 1998, como decorrência da fragilidade do sistema financeiro nacional ( $\mathrm{SFN}$ ), em parte relacionada ao efeito contágio das crises cambiais e financeiras do leste asiático e da Rússia, as taxas de juros elevaram-se abruptamente e, por conseguinte, o crédito bancário contraiu-se.

Diante desses acontecimentos, e em sintonia com a tendência de globalização financeira, o SFN passou por um processo de reorganização que se caracterizou tanto pela redução do número de bancos e da presença do setor público quanto pela ampliação do capital estrangeiro. No entanto, a nova conformação não se traduziu em ampliação do volume de crédito bancário, uma vez que a expansão da relação crédito bancário/PIB foi observada apenas a partir de 2005, que pode ser atribuída ao ingresso significativo de capitais internacionais.

Para examinar os motivos pelos quais a reestruturação do SFN não se traduziu em maior eficiência em fornecer liquidez à economia, o Banco Central do Brasil (BCB) instituiu em 1999 o projeto de Juros e Spread Bancário. Com isso, tornou público seu reconhecimento e preocupação com as elevadas taxas de juros praticadas no Brasil, bem como sua intenção em trabalhar pela redução das taxas cobradas pelos bancos nas suas operações de crédito e no diferencial de taxas de captação e aplicação dos recursos.

Também no final da década de 1990, foram adotadas duas medidas que, muito possivelmente, tiveram reflexos sobre a precificação dos juros bancários no Brasil. A primeira delas consistiu na adoção do Sistema de Metas para a Inflação (SMI), formalizando o compromisso com a manutenção do nível geral de preços dentro de um intervalo definido e, para atingir tal objetivo, utilizando a taxa de juros de curto prazo como principal instrumento de política monetária. A condução dessa política resultou, por um lado, na confiança do SFN relativamente à atuação do BCB para a convergência da taxa de inflação à meta estabelecida e, portanto, redução da incerteza sobre os preços. Por outro lado, significou que a taxa de juros de curto prazo apresentaria o nível necessário para acomodação 
da taxa de inflação, o que, em princípio, poderia induzir à maior volatilidade na taxa básica de juros, Selic, e à ampliação da incerteza sobre os juros ${ }^{1}$.

A segunda medida consistiu na instituição pelo BCB de um bureau de crédito, a Central de Risco de Crédito (CRC), substituída posteriormente pelo Sistema de Informações de Crédito (SCR). Apesar de objetivar, primordialmente, o fornecimento de subsídios para a supervisão bancária, esperava-se que o acesso dos bancos a dados das operações de seus clientes, contratadas com a totalidade das instituições financeiras, tivesse contribuído para a melhoria da qualidade do crédito, induzindo à redução da incerteza por inadimplência e, portanto, a spreads menores.

O objetivo deste artigo consiste em contribuir para a análise dos determinantes da margem líquida de juros da margem líquida de juros do sistema bancário brasileiro. Para tanto, foram analisados alguns desenvolvimentos a partir do modelo teórico proposto por Thomas Ho e Anthony Saunders (1981) que considera a interferência de variáveis macroeconômicas na determinação do spread bancário. Em complementação às aplicações desse modelo à análise da determinação do spread no Brasil, buscou-se verificar se a implementação do SMI e da SCR surtiram efeitos sobre a evolução dos spreads.

Além desta introdução e das considerações finais, o artigo está organizado em duas seções. Na primeira, é apresentada a revisão da literatura selecionada. A segunda apresenta um exercício econométrico para a determinação da margem líquida de juros para o Brasil, em contextos de SMI e de SCR. Para essa seção, foi considerado o spread ex ante, medido pela diferença entre as taxas de aplicação e de captação de recursos e, alternativamente, pela relativização dessa medida.

\section{Revisão da Literatura Selecionada}

O artigo The Determinants of Bank Interest Margins: Theory and Empirical Euidence de Ho e Saunders, publicado em 1981 no Journal of Financial and Quantitative Analysis, constituiu-se em marco no estudo sobre spread bancário. Partindo da constatação de que as margens de juros tornaram-se cada vez mais sensíveis à volatilidade da taxa de juros, os autores propuseram a integração dos modelos de comportamento hedge dos bancos, com modelos de microeconomia bancária, especificamente de maximização da utilidade esperada do lucro (ou da riqueza) do banco, para considerar a influência de variáveis macroeconômicas na determinação do spread.

$1 \quad$ Na ausência de cláusulas de escape, a taxa de juros de curto prazo deve acomodar a variação de preços decorrente de choques de oferta. 
Conforme o referido artigo, o banco é visto como avesso ao risco e negociador do mercado de crédito, atuando como intermediário entre ofertantes e demandantes de fundos. Uma vez que as maturidades dos depósitos e dos empréstimos são estocásticas, existe uma incerteza decorrente do descasamento temporal entre as referidas maturidades e, por conta disso, um custo no processo de intermediação financeira, definido como o spread puro da operação. Isso ocorre devido à possibilidade dos bancos terem que recorrer ao mercado interbancário, quer para refinanciamento, em caso de excesso de demanda por empréstimos, quer para reinvestimento, no caso de excesso de oferta de depósitos, ocasiões em que incorrerão com o risco de alteração da taxa de juros.

Ademais, o modelo prevê que os bancos são livres para determinarem os preços de suas operações ativas e passivas, de forma a embutirem uma taxa de provisão pela incerteza decorrente do seu descasamento temporal.

Em termos analíticos,

$$
\begin{aligned}
& P_{L}=p-b ; \mathrm{e} \\
& P_{D}=p+a,
\end{aligned}
$$

em que $p$ é o preço "verdadeiro" da operação e $a$ e $b$ são as taxas de juros que o banco cobra por acolher de imediato o depósito ou a contratação de empréstimo.

Note-se que os preços são inversamente relacionados com a taxa de juros: uma elevação no preço da operação implica redução nos juros. Dessa forma, ainda que os bancos aceitem as operações de forma passiva, as probabilidades de um novo depósito $\left(\lambda_{\mathrm{a}}\right)$ e de um novo empréstimo $\left(\lambda_{\mathrm{b}}\right)$ serão influenciadas pelas suas decisões no que tange aos preços, especificamente sobre o spread $a+b .^{2}$

A maximização da utilidade esperada do lucro (ou da riqueza) implicará spread ótimo, tal que:

$$
s=a+b=\alpha / \beta+1 / 2 R \sigma^{2}{ }_{1} Q,
$$

sendo: $\alpha / \beta$ a razão entre o intercepto e a inclinação das curvas de demanda e de oferta dos bancos; R o coeficiente de aversão absoluta ao risco do banco, - U"/U'; $\sigma_{I}^{2}$ a variância da taxa de juros; e $Q$ o tamanho das operações do banco.

Além da margem decorrente da incerteza, o spread puro, a margem de taxa de juros do banco dependerá da estrutura de mercado, do grau de aversão ao risco do banco, da variância das taxas de juros e do tamanho médio das transações. Assim, quanto mais inelásticas forem as curvas de demanda e de oferta de fundos, menos competitivos serão os mercados. Por sua vez, quanto mais avesso ao risco for o banco, mais volátil for a taxa de juros e maior for o tamanho

2 Os autores supõem que as funções de oferta de depósitos e de demanda por empréstimos são simétricas e lineares, tais que: $\lambda \mathrm{a}=\alpha-\beta \mathrm{a}$ e $\lambda \mathrm{b}=\alpha-\beta \mathrm{b}$. 
médio das operações dos bancos, maior será o spread requerido para maximizar a utilidade esperada da riqueza (ou do lucro) do banco.

A modelagem é proposta em dois estágios. Após a estimação do spread puro, esse é regredido com outras variáveis que interferem no spread observado. Nos testes empíricos realizados, Ho e Saunders (1981) levaram em conta o que consideraram três imperfeições institucionais, quais sejam: o pagamento implícito de juros, o custo de oportunidade das reservas e o risco de inadimplência sobre empréstimos. Os resultados alcançados, com base em amostra dos cem maiores bancos norte-americanos, permitiram aos autores concluir que o spread puro (decorrente da incerteza) e o pagamento implícito de juros (decorrente da isenção de tarifas para determinados cliente, por exemplo) são significativos, enquanto os depósitos compulsórios e a inadimplência não o são. Ainda sobre variações do spread puro, Ho e Saunders (1981, p. 590) argumentam que:

[...] the estimated pure spread varied over time from quarter to quarter [...] If it is assumed, however, as seems reasonable, that the coefficient of risk aversion, the size of transactions and market structure change relatively slowly over time compared to interest rate changes, then we might expect the quarterly time series behavior of the estimated pure spreads to be large dependent on changes in the volatility or variability of interest rates.

Saunders e Schumacher (2000) aplicaram o modelo de Ho e Saunders para uma análise cross-country da margem líquida de taxa de juros em seis países europeus e nos Estados Unidos, durante o período de 1988 a 1995. Os autores consideraram como determinantes microeconômicos o pagamento implícito de juros, o custo de oportunidade das reservas e o requerimento de capital próprio, sendo que os resultados empíricos mostraram-se significativos para as três variáveis, com destaque para o pagamento implícito de juros, evidenciando que, para financiá-lo, os bancos ou elevam as taxas de juros dos empréstimos ou reduzem as taxas dos depósitos remunerados.

Foi realizada também análise dos efeitos da estrutura de mercado e da volatilidade da taxa de juros em cada país selecionado. Nesse particular, conforme os autores (2000, p. 820), "[...] this methodology will allow us to separate the effects on NIM for which macro-economic policies are responsible (such as interest-rate volatility) and components of the margin for which market structure (monopoly power) is responsible"3. As conclusões de Saunders e Schumacher (2000) são que, por um lado, mercados bancários mais competitivos implicam spreads menores, relativamente aos menos competitivos e, por outro lado, em relação à volatilidade da taxa de juros, a estimação permitiu afirmar que

3 NIM é a sigla para Net Interest Margin, ou margem líquida de juros. 
aumentos na volatilidade da taxa de juros, tanto de curto quanto de longo prazo, contribuíram para elevação do spread.

Partindo do proposto por Ho e Saunders (1981), Maudos e Guevara (2004) ampliaram o estudo dos determinantes do spread bancário em cinco países europeus (Alemanha, França, Reino Unido, Itália e Espanha) entre 1993 e 2000. Segundo os autores, há uma interpretação equivocada de que a redução da margem de juros na Europa nesse período tenha decorrido exclusivamente da redução da concorrência no setor. Assim, os autores propuseram-se examinar os determinantes dessa margem, tendo em vista que ela depende também de outros fatores como risco dos juros e de crédito e a evolução dos custos operacionais, dentre outros, de forma a mostrar que a redução do spread, teoricamente, é compatível com a contração do grau de concorrência entre os bancos.

Nesse sentido, Maudos e Guevara (2004) identificaram os elementos fundamentais que afetam a margem de juros, a partir da maximização da utilidade esperada do lucro. Da mesma forma que no trabalho original de Ho e Saunders (1981), os bancos são definidos como avessos ao risco e simples intermediários entre ofertantes e demandantes de crédito. Tendo em vista que depósitos e empréstimos não são sincronizados e a taxa de juros permanece ao longo do período considerado, os bancos determinam as taxas de juros paga e cobrada do cliente, respectivamente, abaixo e acima da taxa de juros do mercado financeiro, visando minimizar o risco de perda, em caso de ter que recorrer ao mercado, quer para aplicar as sobras não emprestadas, quer para buscar recursos, em caso de uma maior demanda de fundos.

Analiticamente:

$$
\begin{gathered}
r_{D}=r-a ; \\
r_{L}=r+b ; \mathrm{e} \\
s=r_{L}-r_{D}=a+b .
\end{gathered}
$$

Assim, o spread (s) é a diferença entre a taxa de juros de empréstimos e a taxa de remuneração dos depósitos, que consiste nas somas dos diferenciais cobrados pelos bancos nas operações ativas $(a)$ e passivas $(b)$, em relação à taxa do mercado $(r)$.

A partir da crítica de Lerner (1981) ao trabalho de Ho e Saunders (1981), Maudos e Guevara (2004) incorporaram ao modelo os custos de produção associados ao processo de intermediação financeira e, atendidas às condições de maximização, chegaram ao spread ótimo, conforme equação que segue: 


$$
s=\frac{1}{2}\left(\frac{\alpha_{D}}{\beta_{D}}+\frac{\alpha_{L}}{\beta_{L}}\right)+\frac{1}{2}\left(\frac{C(L)}{L}+\frac{C(D)}{D}\right)-\frac{1 U^{\prime \prime}}{4 U^{\prime}(\bar{W})}\left[\left(L+2 L_{0}\right) \sigma_{L}^{2}+(L+D) \sigma_{M}^{2}+2\left(M_{0}-L\right) \sigma_{L M}\right]
$$

De acordo com o modelo, são os seguintes os determinantes da margem de juros:

a) estrutura de mercado, que depende de $\beta$, correspondente à elasticidade da demanda por empréstimos e da oferta de depósitos, de forma que quanto menor o coeficiente maior a capacidade de exercício do poder de monopólio;

b) custo operacional médio $(C(L) / L$ e $C(D) / D)$, de forma que quanto maiores os custos, mais altas deverão ser os spreads bancários para cobri-los;

c) aversão ao risco, cuja expressão absoluta é - U"(W)/U'(W). Quanto mais avesso ao risco for o banco, maior será a margem líquida de juros;

d) volatilidade da taxa de juros do mercado financeiro $\left(\sigma^{2} \mathrm{M}\right)$, sendo que quanto mais volátil a referida taxa, maior será o risco de mercado;

e) risco de crédito, capturado pela variável $\sigma 2 \mathrm{~L}$, e decorrente da possibilidade de default de parte das operações.

Na modelagem em um "único estágio", Maudos e Guevara (2004) trabalharam com proxies dos determinantes acima relacionados, respectivamente, os índices de Herfindahl e o de Lerner para a estrutura de mercado, a relação entre despesas operacionais e ativos totais para custos e a relação entre patrimônio líquido e ativos totais como proxy do grau de aversão ao risco. A volatilidade da taxa de juros foi estimada pelo desvio padrão de dados diários de taxas de juros de três títulos públicos com diferentes maturidades e, como proxy para o risco de crédito, foi utilizada a relação entre empréstimos e ativos totais. Além dessas variáveis, foram considerados ainda: a interação entre o risco de crédito e o risco de mercado, a amplitude das operações, o pagamento implícito de juros, os custos de oportunidade das reservas bancárias e a qualidade do gerenciamento.

Os resultados obtidos, utilizando dados em painel para 1826 bancos, foram estatisticamente significantes e de acordo com o prognóstico esperado. O poder de mercado e o risco da taxa de juros apresentaram sinal positivo e capacidade explicativa na determinação do spread bancário. Por sua vez, o risco de crédito apresentou o sinal esperado, porém pouca capacidade explicativa da variável dependente. Destacou-se no modelo a capacidade explicativa dos custos operacionais. Acerca desse fato, Maudos e Guevara (2004, p. 2272) afirmam que: 
The explanatory capacity of operating costs deserves special mention. The high statistical significance of this variable shows the importance of introducing it into the theoretical explanation of the interest margin as done in the paper. Therefore, there could be a possible omitted variable bias of studies that ignore its importance. As the theoretical model predicts, the banks that bear higher average operating expenses need to operate with higher margins to enable them to offset their higher transformation costs.

Com relação às variáveis introduzidas ad hoc na regressão, destacou-se a qualidade do gerenciamento, cuja proxy foi o custo da taxa de juros, definido como o custo operacional necessário para gerar uma unidade de receita bruta.

Maudos e Guevara (2004) concluíram ainda que o aumento da concentração e a redução da concorrência bancária nos países estudados - que induziriam à ampliação do spread - foram contrabalançados pela queda dos custos operacionais e do risco de crédito no período e, em menor grau, pela baixa volatilidade das taxas de juros.

O comportamento do spread bancário na América Latina foi objeto de estudo elaborado por Brock e Suarez (2001), com dados da Argentina, Bolívia, Colômbia, Chile, México e Peru, em diferentes períodos da década de 1990. Os fatores microeconômicos considerados no "primeiro estágio" contemplaram risco de crédito, requisitos de capital, liquidez e custos operacionais. Os resultados variaram de acordo com cada país; no entanto, os autores destacaram o efeito dos custos operacionais sobre o spread bancário, uma vez que nos seis países examinados o aumento dos custos operacionais induziu a um aumento no spread bancário.

Dentre os determinantes macroeconômicos selecionados - volatilidade da taxa de juros, taxa de inflação e crescimento do PIB -, os resultados indicaram que:

a) a volatilidade dos juros é, geralmente, positivamente correlacionada com o spread puro, com exceção da Colômbia e do Peru;

b) com exceção da Argentina, a taxa de inflação também se mostrou positivamente correlacionada com o spread; e

c) observou-se fraca tendência de que taxas maiores de crescimento do PIB induzissem spreads menores.

A aplicação ao caso brasileiro do modelo de determinação do spread de Ho e Saunders (1981) em "dois estágios" foi proposta por Afanasieff, Lhacer e Nakane (2002), com base em informações entre fevereiro de 1997 e novembro de 2000 de 142 bancos comerciais. Para a definição das taxas, a de depósito consistiu na remuneração posfixada para 30 dias em Certificados de Depósitos Bancários 
(CDB) e a de empréstimos pela média das taxas posfixadas das operações de crédito com recursos livres 4 .

No "primeiro estágio", integraram o vetor de características do banco o número de empregados (proxy do tamanho do banco), a razão entre os depósitos não remunerados e o total de ativos, a razão entre fundos remunerados e o total de ativos remunerados, os custos operacionais, a liquidez do banco, a razão entre a receita de serviços e as receitas totais, o patrimônio líquido do banco e a alavancagem do banco.

$\mathrm{Na}$ estimação do spread puro apresentaram sinal positivo o número de empregados (tamanho do banco), a proporção de depósitos não remunerados, os custos operacionais e a razão entre a receita de serviços e as receitas operacionais. Apresentou sinal negativo a razão entre os fundos remunerados e o ativo.

Contrastando o spread puro estimado com o observado, Afanasieff, Lhacer e Nakane (2002) concluíram que os fatores microeconômicos não são os mais relevantes na sua determinação no Brasil, com possível relevância de fatores macroeconômicos.

No "segundo estágio", o spread puro estimado foi relacionado com um conjunto devariáveis macroeconômicas, quais sejam: a Selic e sua volatilidade, a taxa de inflação (medida pelo IGP-DI) e o crescimento do PIB, cuja proxy foi o índice de produção industrial com ajuste sazonal, calculado pelo IBGE.

Os resultados estimados para a equação de longo prazo sugeriram que o spread bancário aumenta com aumentos na taxa de juros de curto prazo e na taxa de inflação e reduz com o crescimento do PIB. Por sua vez, contrariamente ao esperado pelos autores, a volatilidade da taxa de juros afetou negativamente o spread. Por fim, observam que o alto coeficiente de determinação aponta para a relevância dos fatores macroeconômicos na determinação do spread bancário no Brasil.

Bignotto e Rodrigues (2006) igualmente adotaram o modelo teórico proposto por Ho e Saunders (1981) para analisar os determinantes do spread bancário brasileiro, porém com correção para estimadores fixos com efeito não observável 5 .

A amostra foi composta de dados trimestrais de 87 bancos, para o período de 2001-T1 a 2004-T1, e foram consideradas as seguintes variáveis: custo administrativo, provisões para risco de crédito, ativos líquidos ponderados pelas durations dos títulos em carteira (proxy para risco de juros), market share, liquidez,

$4 \quad$ Segundo Afanasieff, Lhacer e Nakane (2002, p. 12), "[...] most of the literature makes use of reported interest income and interest expenses when computing bank interest margins. The advantage of our measure is that the posted rates are more likely to be influenced and to respond to changes in the economic environment than interest income and expense".

5 Bignotto e Rodrigues (2006) exemplificaram que a aversão ao risco, por exemplo, é não observável, sendo possível supô-la invariável no tempo e de tal relevância que sua não consideração poderia enviesar os demais coeficientes estimados. Os autores adotaram o método de Chamberlaim para a eliminação de variáveis não observáveis. 
receita de serviços, custo do compulsório, despesa tributária, Selic e taxa de inflação, medida pelo IPCA. De acordo com a estimação, o spread foi positivamente influenciado pelos custos administrativos, risco de crédito, risco de juros, receitas de serviços, reservas compulsórias, tamanho do ativo total do banco e Selic. Os coeficientes estimados para o market share e a taxa de inflação influenciaram negativamente o spread. Por fim, as despesas tributárias não apresentaram resultado significativo na regressão.

Partindo do trabalho desenvolvimento por Maudos e Guevara (2004), Oreiro et al. (2006) propuseram o aprofundamento da análise dos determinantes macroeconômicos do spread bancário no Brasil para o período de janeiro de 1995 a dezembro de 2003. Os autores partiram dos resultados obtidos por Afanasieff, Lhacer e Nakane (2002), em especial aqueles de maior relevância em termos macroeconômicos, e analisaram as variáveis testadas a partir de algumas proxies diferenciadas. Assim, foram considerados, além do próprio spread, a volatilidade e o nível da Selic, o produto industrial sem ajuste sazonal, calculado pelo IBGE, e a inflação, medida pelo IPCA.

A relevância das variáveis determinantes e o sentido de causalidade foram estimados com base em funções impulso-resposta do spread a choques em cada uma das variáveis selecionadas. Pelos resultados, o spread foi influenciado positivamente pela volatilidade e nível da Selic, com efeito persistente ao longo de doze meses, e pelo produto industrial. Não se observou influência significativa do spread à taxa de inflação.

Posteriormente, pela decomposição da variância dos erros de previsão após o choque, Oreiro et al. (2006) concluíram que uma parcela significativa da variação do spread bancário após doze meses é explicada pela Selic e pela sua volatilidade. A partir disso, os autores argumentam propositivamente que, tendo em vista que a volatilidade da taxa de juros no mercado interbancário é reflexo da estabilidade econômica do Brasil, o spread poderia ser reduzido por meio de políticas econômicas que diminuíssem tal volatilidade. Ressaltam os autores que, além de interferir por meio do canal de juros, a instabilidade econômica pode afetar o spread bancário por outros dois canais. O primeiro deles é o grau de aversão ao risco: um país com histórico de grande instabilidade econômica deve possuir bancos com elevado grau de aversão ao risco. O segundo é a covariância entre o risco de juros e o risco de crédito, segundo a qual, a variabilidade da taxa básica de juros deverá ser transmitida para o nível de produção real, pelo aumento do nível de inadimplência das operações de crédito. 


\section{Modelo de Determinação do Spread Bancário no Brasil em Contextos de SMl e SCR}

No final da década de 1990, o Brasil aderiu ao SMI e o BCB finalizou a constituição de um bureau de crédito. Ainda que os objetivos fossem a adequação da taxa de inflação para níveis pré-estabelecidos e o aperfeiçoamento da supervisão bancária, respectivamente, é plausível supor que ambas as instituições tenham induzido a mudanças no risco de taxa de juros e no risco de crédito, provocando alterações no spread bancário.

Nesse sentido, no caso do SMI, a ideia é que sua adoção tenha influenciado o nível de spread não somente pela estabilidade dos preços, mas, principalmente, pela menor volatilidade da taxa básica de juros de curto prazo. Por sua vez, com relação ao SCR, a intuição é que os efeitos positivos sobre a redução da margem líquida de juros decorreram da menor assimetria de informações no sistema bancário.

O exercício de determinação do spread bancário apresentado nesta seção apoiou-se no modelo de Ho e Saunders (1981), na ampliação proposta por Maudos e Guevara (2000) e nas aplicações para o caso brasileiro das contribuições desses autores, conforme foram desenvolvidas por Afanasieff, Lhacer e Nakane (2002) e Oreiro et al. (2006). Adicionalmente, examinou-se os efeitos sobre o spread bancário a partir da adoção do SMI e da implantação do SCR. Em relação à adoção do SMI, não se espera efeito líquido desse Sistema, pelo menos a priori, uma vez que, em tese, a política monetária de acomodação do nível de preços provoca maior nível e volatilidade da Selic, enquanto espera-se impacto positivo sobre a redução dos spreads, a partir da implantação da SCR

Para tanto, considerando que o objetivo do presente exercício é a identificação das principais variáveis com capacidade explicativa, optou-se por regressão em um "único estágio" para estimação do spread bancário total', contemplando 172 meses, de janeiro de 1995 a abril de 2009.

Além da estimação do efeito induzido pelo SMI e SCR, fazem parte do modelo as seguintes variáveis?:

$6 \quad$ Os dois estágios propostos por Ho e Saunders (1981) permitem a identificação do spread puro. Para maiores detalhes, ver seção anterior. A elaboração em um único estágio segue o proposto por Maudos e Guevara (2004).

7 Apesar de o modelo de Ho e Saunders (1981) permitir a inclusão de muitas variáveis, não foram consideradas as razões entre crédito com recursos livres e PIB, crédito com recursos livres e créditos totais, créditos livres concedidos por bancos públicos e créditos livres totais, para evitar o problema de endogenia entre as variáveis. Tais relações, entre outras, foram tratadas em Demirguç-Kunt e Huizinga (1999). 
a) Spread: spread médio préfixado das operações de crédito com recursos livres. Retirado do Sistema Gerenciador de Séries Temporais (SGS) do BCB, série $3955^{\circ}$;

b) Taxa de inflação (ipca): variação mensal do IPCA do IBGE. Retirado do Sistema IBGE de Recuperação Automática (SIDRA), Tabela 1737;

c) Taxa de juros de curto prazo (Selic): taxa acumulada no mês, anualizada. Retirado do SGS do BCB, Série 4189;

d) Volatilidade da taxa de juros Selic (vol_Selic): calculada através de um modelo AR(1)- GARCH $(1,1)^{9}$;

e) Produção industrial (lnpim): logaritmo natural do índice dessazonalizado da Pesquisa Industrial Mensal - Produção Física do IBGE. Índice retirado do Sidra, Tabela 2295;

f) Spread soberano (rsksbr): média mensal do spread do C-Bond até dezembro de 2003 e do Global-40, a partir de janeiro de $2004,{ }^{10}$ divulgados pelo Ipeadata;

g) Taxa de inadimplência (inadimpl): razão entre o saldo das operações de crédito risco 2 e o saldo total das operações de crédito do sistema financeiro. Construída a partir das séries 2052 e 4422 do SGS do BCB;

h) Recolhimentos compulsórios sobre depósitos à vista (compuls): razão entre os recolhimentos sobre depósitos à vista e a média dos depósitos à vista. Construída a partir das séries 1823 e 1849 do SGS do BCB;

i) Imposto sobre Operações Financeiras (IOF) (iof_op): razão entre o saldo da conta 4.9.1.10.10-2 (IOF a recolher sobre operações de crédito) do Plano Contábil das Instituições do Sistema Financeiro Nacional (Cosif) e o volume de operações de crédito do SFN, série 2052 do SGS do BCB;

j) Despesas administrativas (desp_adm): razão entre os saldos das contas 8.1.7.00.00-6 (Despesas Administrativas) e 1.00.00.00-7 (Ativo Circulante e Realizável a Longo Prazo) do Cosif;

k) Market share (rc3): razão entre o ativo circulante e realizável a longo prazo dos três maiores bancos e o ativo circulante e realizável a longo prazo da área bancária. Conta 1.00.00.00-7 (Circulante e Realizável a Longo Prazo) do Cosif.

$8 \quad$ Essa medida considera o diferencial entre as taxas de empréstimo e de depósito, ponderadas pelo volume das operações. Alternativamente, será apresentado exercício de relativização da taxa.

9 A volatilidade foi estimada por um modelo autorregressivo de heteroscedasticidade condicional generalizada (GARCH), tendo em vista que a variância não é constante no tempo. O modelo GARCH “[...] é a generalização do modelo $\mathrm{ARCH}$, no qual a variância condicional de $\mathrm{n}$ no instante $t$ depende não somente de perturbações ao quadrado passadas, mas também de variâncias condicionais passadas" (GUJARATI, 2006, p. 440).

10 Lançado em 1994, o C-Bond foi, durante muitos anos, o título da dívida brasileira mais negociado no mercado internacional. Por sua vez, o título Global 40 (ou Global 2040, por ser este o seu ano de vencimento) foi lançado em 2000 e, a partir de 2004, tornou-se o papel brasileiro de maior liquidez no exterior. 
Para verificar a estacionariedade das séries, utilizou-se o teste de raiz unitária de Dickey-Fuller Aumentado (ADF), tomando como referência o critério de Schwartz ${ }^{11}$. Não é demais ressaltar que a utilização dos modelos de regressão envolvendo séries temporais não estacionárias poderia conduzir ao problema de regressão espúria, apesar das estatísticas convencionais - teste-t, teste- $\mathrm{F}$ e $\mathrm{R}^{2}$ - indicarem valores significativos, pois a presença de tendência, decrescente ou crescente, indicaria alto coeficiente de determinação, sem implicar, necessariamente, relação entre séries (GUJARATI, 2006).

Pelos resultados, a variável dependente mostrou-se estacionária em nível, com intercepto. A estacionariedade em nível igualmente foi observada em despesas administrativas, IPCA, produção industrial, Selic e volatilidade da Selic e as demais variáveis tornaram-se estacionárias após a primeira diferença. Os resultados apresentados na Tabela 1 atenderam ao critério de relevância da inclusão (ou não) de intercepto e tendência, consoante estatística-t dessas variáveis.

Tabela 1 - Teste de raiz unitária

\begin{tabular}{|c|c|c|c|c|c|c|}
\hline \multirow{2}{*}{ Variável } & \multicolumn{2}{|c|}{$\begin{array}{l}\text { Com intercepto } \\
\text { e tendência }\end{array}$} & \multicolumn{2}{|c|}{ Com intercepto } & \multicolumn{2}{|c|}{$\begin{array}{l}\text { Sem intercepto } \\
\text { e tendência }\end{array}$} \\
\hline & Em nível & $\begin{array}{c}1^{\mathbf{a}} \\
\text { diferença }\end{array}$ & Em nivel & $\begin{array}{c}1^{\mathbf{a}} \\
\text { diferença }\end{array}$ & Em nivel & $\begin{array}{c}1^{\mathbf{a}} \\
\text { diferença }\end{array}$ \\
\hline compuls & & & & & & $-10,70797$ \\
\hline desp_adm & $-4,52967$ & & & & & \\
\hline inadimpl & & & & & & $-9,14133$ \\
\hline iof_op & & & & & & $-13,21656$ \\
\hline ipca & & & $-5,31286$ & & & \\
\hline inpim & $-3,68862$ & & & & & \\
\hline $\mathrm{rc} 3$ & & & & $-15,52945$ & & \\
\hline rsksbr & & & & & & $-8,82122$ \\
\hline selic & $-3,66044$ & & & & & \\
\hline spread & & & $-3,93722$ & & & \\
\hline vol_selic & & & & & $-6,08306$ & \\
\hline
\end{tabular}

Fonte: EViews 6.0.

Nota: foram considerados os valores críticos da estatística $t$ a $5 \%$ de significância.

A partir das séries estacionárias, estimou-se o spread, cuja primeira especificação passou a ser a seguinte:

SPREAD $=a^{*}$ D(COMPULS) $+\beta^{*}$ DESP_ADM $+\chi^{*}$ D(INADIMPL) + $\delta^{*}$ IOF_OP $+\varepsilon^{*}$ IPCA $+\varphi^{*}$ LNPIM $+\gamma^{*}$ D(RC3) $+\eta^{*}$ SELIC $+\imath^{*}$ D(RSKSBR $)+$ $\phi * \mathrm{VOL}$ SELIC $+\kappa^{*} \mathrm{SCR}+\lambda^{*} \mathrm{SMI}+\mu$

11 Os testes foram realizados com o software econométrico EViews. 
A regressão foi executada em um único estágio, tendo em vista que se quer estimar o spread total observado. Além das variáveis exógenas ao modelo, foram consideradas duas dummies de tempo para tratar das alterações promovidas tanto na sistemática da política monetária quanto no acesso ao conteúdo informacional do cliente bancário, respectivamente, SMI e SCR. As estimativas, conforme a Tabela 2 , foram as que seguem:

Tabela 2 - Estimativa do spread (primeira especificação)

\begin{tabular}{ccccc}
\hline Variable & Coefficient & Std. Error & t-Statistic & Prob. \\
\hline D(COMPULS) & 0,01908 & 0,05473 & 0,34864 & 0,7278 \\
DESP_ADM & 15,21563 & 10,88725 & 1,39756 & 0,1642 \\
D(INADIMPL) & 5,72417 & 1,43872 & 3,97866 & 0,0001 \\
IOF_OP & 423,2292 & 96,13770 & 4,40232 & 0,0000 \\
IPCA & 1,50612 & 1,44462 & 1,04258 & 0,2987 \\
LNPIM & $-25,69674$ & 10,26741 & $-2,50275$ & 0,0133 \\
D(RC3) & $-0,78960$ & 0,79167 & $-0,99738$ & 0,3201 \\
SELIC & 1,01879 & 0,09353 & 10,89278 & 0,0000 \\
D(RSKSBR) & 0,00103 & 0,00622 & 0,16619 & 0,8682 \\
VOL_SELIC & 2,56020 & 0,26628 & 9,61486 & 0,0000 \\
SCR & 6,27836 & 4,09713 & 1,53238 & 0,1274 \\
SMI & 7,73082 & 4,21421 & 1,83447 & 0,0685 \\
C & 113,02640 & 48,33589 & 2,33835 & 0,0206 \\
R-squared & 0.925684 & \multicolumn{2}{c}{ F-statistic } & 162.9665 \\
Durbin-Watson stat & 0.642074 & Prob(F-statistic) & 0.000000 \\
\hline
\end{tabular}

Fonte: EViews 6.0.

De acordo com este primeiro exercício, as determinantes do spread bancário seriam a inadimplência, a razão entre o IOF e o volume de operações de crédito, a produção industrial, a Selic e sua volatilidade. Entretanto, os resultados indicaram presença de autocorrelação de primeira ordem dos resíduos, conforme estatística DurbinWatson (DW). Na regressão estimada, os valores críticos para um nível de significância de 5\%, extrapolando para o número de observações da amostra, seriam 1,773 e 2,162 para dL e dU, respectivamente. Um valor bem abaixo, como o DW da regressão, faz com que se rejeite a hipótese de ausência de correlação serial positiva. ${ }^{12}$

12 A autocorrelação é um dos problemas mais enfrentados na análise de séries temporais e viola o pressuposto de resíduos não correlacionados (white noise). Dentre as possíveis causas da autocorrelação estão: inércia das séries, viés de especificação (quer por falta de variáveis determinantes, quer por incorreta relação funcional) e defasagem nos efeitos das variáveis. 
Assim, o primeiro procedimento de correção sugerido foi por meio dos estimadores de Newey-West. ${ }^{13}$ Considerando um nível de significância de $5 \%$, não houve alteração no número de variáveis determinantes do spread bancário, conforme mostra a Tabela 3.

Tabela 3 - Estimativa do spread (correção NW)

\begin{tabular}{ccccc}
\hline Variable & Coefficient & Std. Error & t-Statistic & Prob. \\
\hline D(COMPULS) & 0,01908 & 0,04418 & 0,43191 & 0,66640 \\
DESP_ADM & 15,21563 & 14,30828 & 1,06342 & 0,28920 \\
D(INADIMPL) & 5,72417 & 2,46373 & 2,32338 & 0,02140 \\
IOF-OP & 423,22920 & 159,77180 & 2,64895 & 0,00890 \\
IPCA & 1,50612 & 1,77212 & 0,84990 & 0,39670 \\
LNPIM & $-25,69674$ & 10,64938 & $-2,41298$ & 0,01700 \\
D(RC3) & $-0,78960$ & 0,91583 & $-0,86217$ & 0,38990 \\
SELIC & 1,01879 & 0,17480 & 5,82842 & 0,00000 \\
D(RSKSBR) & 0,00103 & 0,00471 & 0,21497 & 0,82660 \\
VOL_SELIC & 2,56020 & 0,48423 & 5,28720 & 0,00000 \\
SCR & 6,27836 & 4,92437 & 1,27496 & 0,20420 \\
SMI & 7,73082 & 4,30568 & 1,79549 & 0,07450 \\
C & 113,02640 & 47,94037 & 2,35765 & 0,01960 \\
R-squared & 0,925684 & \multicolumn{2}{c}{ F-statistic } & 192.9665 \\
Durbin-Watson & 0.642074 & Prob (F-statistic) & 0.00000 \\
stat & \multicolumn{2}{c}{}
\end{tabular}

Fonte: EViews 6.0.

Considerando as variáveis determinantes em nível de significância de 5\%, observou-se que os sinais de seus coeficientes comportaram-se de acordo com o esperado, ou seja: variações na inadimplência, IOF, ${ }^{14}$ Selic e volatilidade da Selic provocaram variações de igual sentido no spread bancário. De outra parte, aumento na produção industrial acarretou redução na margem de juros, o que pode estar indicando maior capacidade de financiamento com recursos próprios e, portanto, menor demanda por crédito bancário. ${ }^{15}$

13 Newey e West (1987) propuseram um estimador geral da covariância que é consistente com a presença de heterocedasticidade e de autocorrelação. Essa correção presta-se a grandes amostras.

14 A magnitude do coeficiente do IOF deveu-se à pequena dimensão da variável - que está relativizada pelo ativo -, comparativamente à variável dependente.

15 Exercícios adicionais foram realizados, incluindo as determinantes com significância a $5 \%$ e as dummies de tempo. As inferências apontaram para a significância do SMI como determinante do spread bancário. 
O spread estimado mostrou-se bem ajustado à variável observada, de acordo com o coeficiente de determinação da regressão $\left(R^{2}\right)$, indicando que $92,57 \%$ do spread bancário pode ser explicado pelas variáveis significativas do modelo. A boa aderência dos resultados da estimação pode ser visualizada no Gráfico 1.

Gráfico 1 - Spread observado e estimado

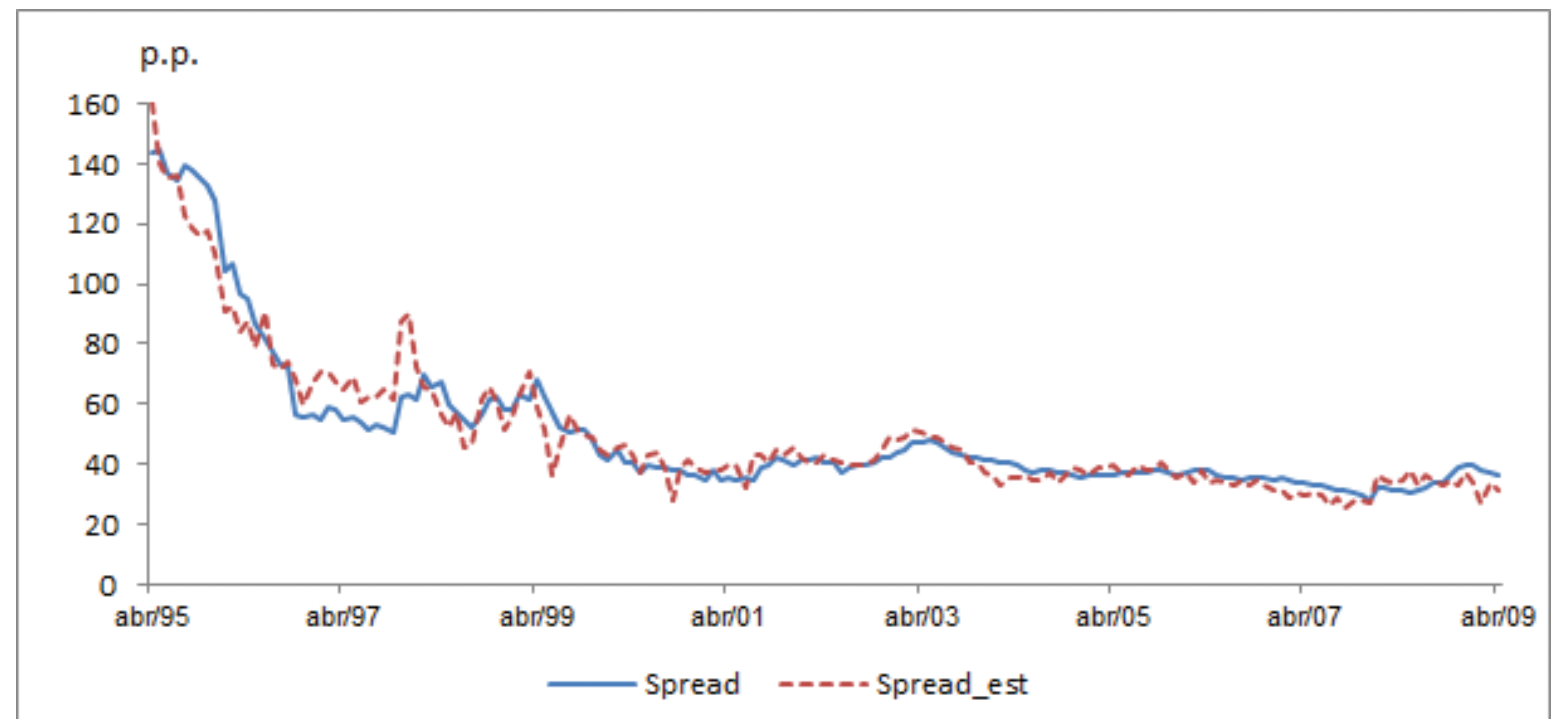

Fonte: BCB (2009) e EViews 6.0.

Uma alternativa para o problema de autocorrelação dos resíduos residiu em trabalhar com o modelo nas primeiras diferenças, de forma a excluir a tendência no processo de estimação, conforme sugestão de Maddala (2003). A vantagem desse método é que se evita problemas de classificação errada da variável dependente como estacionária, gerando regressão com séries não estacionárias. A equação passa a ser especificada por:

$\mathrm{D}($ SPREAD $)=a^{*} \mathrm{D}(\mathrm{COMPULS})+\beta^{*} \mathrm{D}($ DESP_ADM $)+\chi^{*} \mathrm{D}$ (INADIMPL) $+\delta^{*} \mathrm{D}\left(\mathrm{IOF} \mathrm{OP}_{-}\right)+\varepsilon^{*} \mathrm{D}(\mathrm{IPCA})+\varphi^{*} \mathrm{D}(\mathrm{LNPIM})+\gamma^{*} \mathrm{D}(\mathrm{RC} 3)+\eta^{*} \mathrm{D}(\mathrm{SELIC})+$ $\imath^{*} \mathrm{D}($ RSKSBR $)+\phi^{*} \mathrm{D}($ VOL_SELIC $)+\mathrm{k}^{*} \mathrm{D}(\mathrm{SCR})+\lambda^{*} \mathrm{D}(\mathrm{SMI})+\mu$

No entanto, a retirada da tendência implicaria perda de informações sobre a relação de longo prazo das variáveis. Para equacionar esse problema, de forma a recuperar a informação de mais longo prazo, a solução proposta foi a regressão cointegrada, com a formulação de modelo de correção de erros (MCE) no modelo dinâmico. A interpretação econômica da cointegração é que se as variáveis do modelo possuem uma relação de longo prazo, elas devem evoluir de forma estável no tempo. Em outras palavras, mesmo que as séries possuam tendências estocásticas, a diferença entre elas será estacionária (HARRIS, 1995).

Dessa maneira, o procedimento consistiu na estimação com todas as variáveis em nível, seguido do teste da estacionariedade do resíduo e da incor- 
poração do resíduo à equação das diferenças. A estacionariedade dos resíduos indica que as variáveis analisadas possuem relacionamento de longo prazo e que existe um modelo de correção de erro que faz a ligação entre a dinâmica de curto prazo com a de longo prazo; isto é, se permite combinar as vantagens de se modelar tanto nas diferenças quanto em nível (GUJARATI, 2006).

O teste de ADF para os resíduos da regressão em nível, consoante Tabela 4, indicou a existência de cointegração entre as séries, afastando a hipótese de regressão espúria. Logo, os coeficientes da regressão são consistentes, mas a distribuição deles não é normal. ${ }^{16}$

Tabela 4 - Teste ADF para o resíduo

\begin{tabular}{cccc}
\hline & & t-Statistic & Prob. $^{*}$ \\
\hline Argumented Dickey-Fuller test statistic & $-5,600906$ & 0,0000 \\
Test critical values: & 1\% level & -2.578717 & \\
& $5 \%$ level & -1.942722 & \\
& $10 \%$ level & -1.615453 & \\
\hline
\end{tabular}

Fonte: EViews 6.0.

Nota: (*) MacKinnon (1996).

Incorporando o mecanismo de correção de erros ao modelo em primeira diferença, a equação de determinação do spread passa a ser especificada como:

SPREAD $=\alpha^{*} \mathrm{D}(\mathrm{COMPULS})+\beta^{*} \mathrm{D}(\mathrm{DESP} A \mathrm{ADM})+\chi^{*} \mathrm{D}(\mathrm{INADIMPL})+\delta^{*} \mathrm{D}(\mathrm{IOF}$ OP) $+\varepsilon^{*}$ D(IPCA) $+\varphi^{*}$ D (LNPIM) $+\gamma^{*}$ D(RC3) $+\eta^{*}$ D(SELIC $)+\imath^{*}$ (RSKSBR $)+$ $\phi^{*} \mathrm{D}($ VOL_SELIC $)+\kappa^{*} \mathrm{D}(\mathrm{SCR})+\lambda^{*} \mathrm{D}(\mathrm{SMI})+\mu+v(-1)$,

onde $v$ é o resíduo da equação em nível.

A nova estimação foi realizada com a incorporação do MCE e os resultados, considerando o p-value a 5\% de significância, conforme sintetizados na Tabela 5, sugerem que as variáveis determinantes do spread bancário são o nível e a volatilidade da Selic, o IOF e a inadimplência das operações. Essas variáveis apresentaram efeitos positivos e de acordo com o esperado. Assim, um aumento em alguma delas acarretará ampliação da variável endógena. Adicionalmente, observa-se que a inclusão de dummies para o SCR e o SMI não agregou informações ao modelo, além daquelas consideradas pelas demais variáveis.

16 O fato de a distribuição dos coeficientes não ser normal, significa que os p-values não são confiáveis como calculados de modo usual pelos softwares. 
Tabela 5 - Estimação do spread com MCE

\begin{tabular}{ccccc}
\hline Variable & Coefficient & Std. Error & t-Statistic & Prob. \\
\hline D(COMPULS) & 0,006208 & 0,021536 & 0,288266 & 0,773500 \\
D(DESP_ADM) & 3,931710 & 3,555017 & 1,105961 & 0,270500 \\
D(INADIMPL) & 1,440850 & 0,560371 & 2,571243 & 0,011100 \\
D(IOF_OP) & 130,941900 & 36,077050 & 3,629507 & 0,000400 \\
D(IPCA) & $-0,320444$ & 0,557347 & $-0,574946$ & 0,566200 \\
D(LNPIM) & $-17,693940$ & 9,305830 & $-1,901383$ & 0,059100 \\
D(RC3) & 0,277488 & 0,290821 & 0,954153 & 0,341500 \\
D(RSKSBR) & 0,000339 & 0,002308 & 0,147005 & 0,883300 \\
D(SELIC) & 0,320719 & 0,052595 & 6,097909 & 0,000000 \\
D(VOL_SELIC) & 2,670765 & 0,697129 & 3,831091 & 0,000200 \\
D(SCR) & $-0,870038$ & 3,019971 & $-0,288095$ & 0,773700 \\
D(SMI) & $-0,681676$ & 2,892433 & $-0,235676$ & 0,814000 \\
RESID01(-1) & 0,244012 & 0,038169 & $-6,392947$ & 0,000000 \\
C & $-0,119420$ & 0,233359 & $-0,511743$ & 0,609600 \\
R-squared & 0,421336 & F-statistic & & 8.681421 \\
Durbin-Watson & 2.024469 & Prob(F-statistic) & & 0.000000 \\
stat & & & \\
\hline
\end{tabular}

Fonte: EViews 6.0.

Comparativamente ao primeiro exercício realizado, note-se que houve concordância com relação às variáveis analisadas, com exceção da produção industrial que teve a p-value aumentado na estimação em primeira diferença, mas manteve sentido de causalidade inversa entre essa variável - aqui tratada como proxy do nível de atividade - e o spread.

Ademais, percebe-se pelo $\mathrm{R}^{2}$ da regressão que $42,13 \%$ da variância do crescimento do spread bancário são explicadas pelas variáveis determinantes incorporadas no modelo. A variação do spread estimado é contrastado com a do observado no Gráfico 2. 


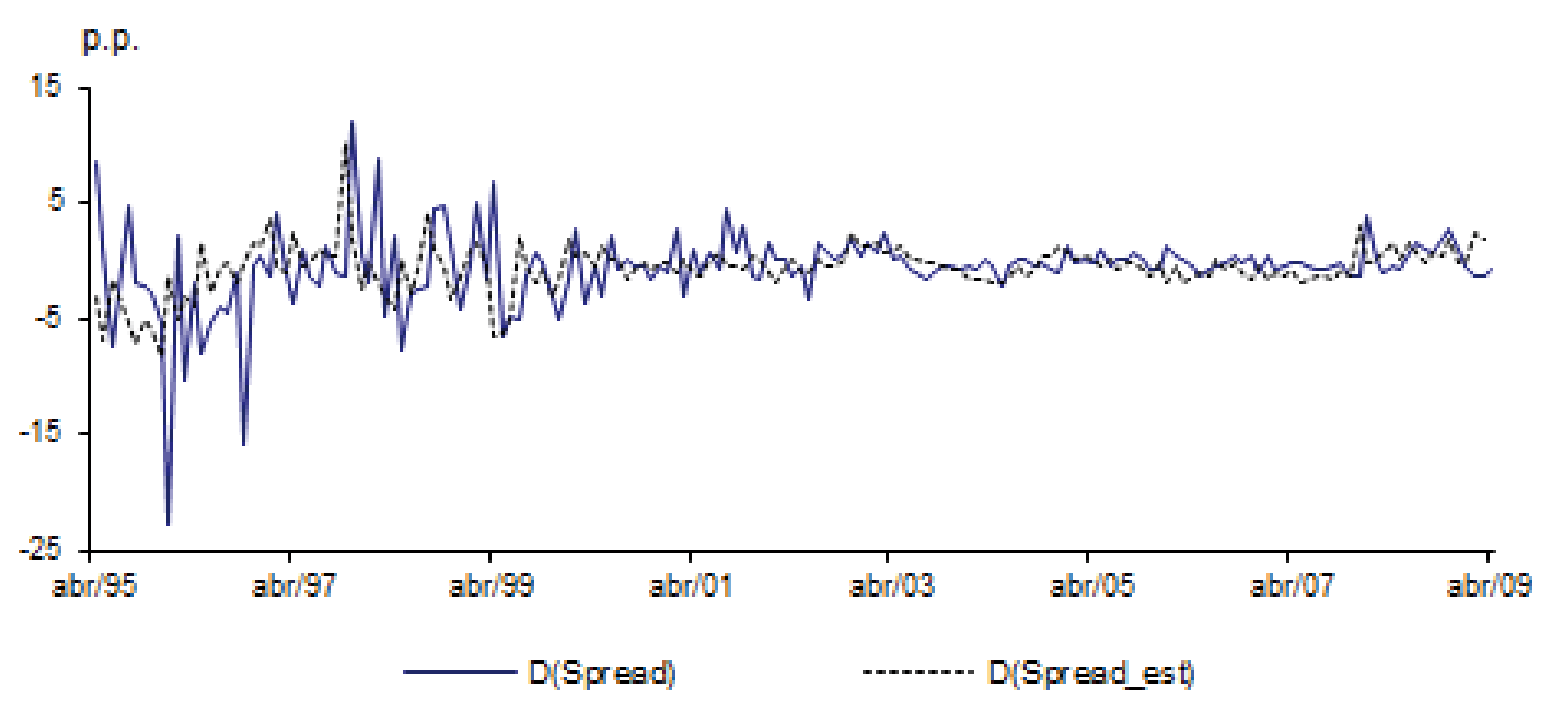

Fonte: EViews 6.0.

De acordo com a plotagem dos resíduos, o modelo "errou" na estimação do primeiro quinquênio. Ademais, as dummies inseridas para o SMI e o SCR não se mostraram significativas, sugerindo que as mudanças ocorridas não ocorreram no patamar das variáveis, mas na relação entre as variáveis determinante e o spread bancário. Por sua vez, a maior variância antes da introdução das dummies sugere que essas influenciaram a determinação da margem líquida de juros. O Gráfico 3 apresenta o erro na estimação e introduz o teste da quebra estrutural.

Gráfico 3 - Resíduos de estimação por cointegração

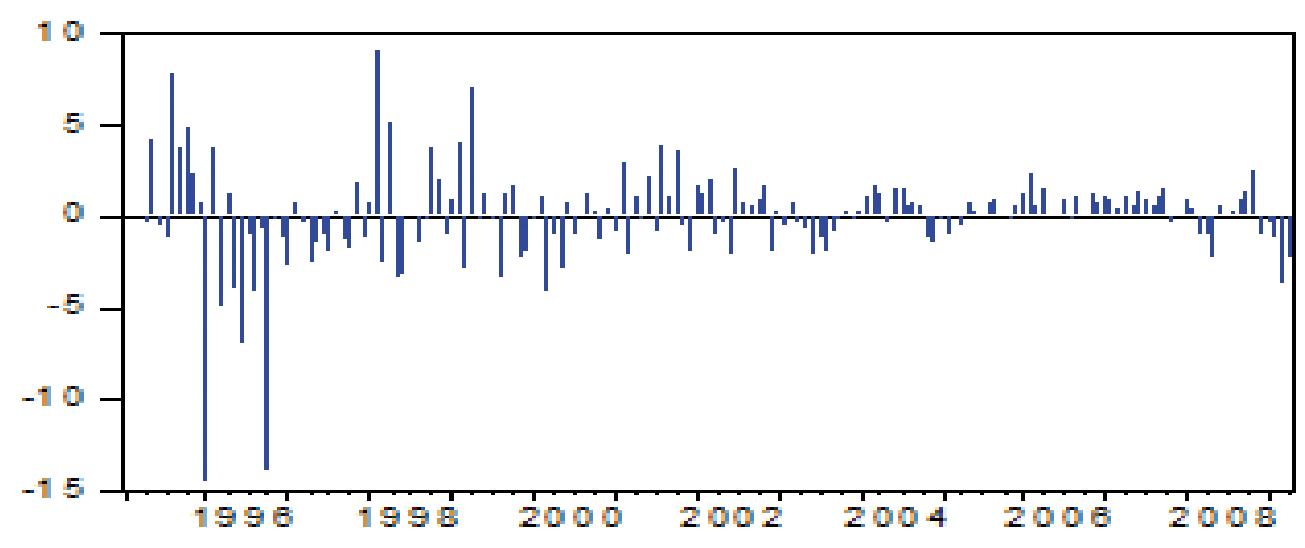

Fonte: EViews 6.0.

Muito embora o spread bancário tenha assinalado menores níveis em período que coincidiu com a implantação do SMI e SCR, o teste de estabilidade 
de Chow, conforme Tabela 6, não permite concluir que tenha havido mudança estrutural no modelo de estimação.

Tabela 6 - Teste de estabilidade de Chow

\begin{tabular}{c|c|c|c}
\hline F-statistic & 1.224058 & Probability & 0.271930 \\
Log likelihood ratio & 16.30725 & Probability & 0.177565 \\
\hline
\end{tabular}

Fonte: EViews 6.0.

Os métodos de estimação utilizados apresentaram resultados robustos e indicaram como variáveis determinantes do spread bancário a inadimplência, o IOF, a Selic e a volatilidade da Selic. Resultados similares foram obtidos quando se estimou com ma diferente medida da variável dependente, relativizada pela taxa de depósitos. Analiticamente:

Spread $=$ (Taxa de empréstimo - taxa de depósito $) /$ Taxa de depósito.

De acordo com essa variável, o comportamento do spread diferiu substancialmente da variável medida pelo diferencial de percentuais. Conforme mostra o Gráfico 4, houve uma tendência de redução do spread até 2002 e forte reversão dessa tendência a partir de 2003. Essa refletiu a queda da taxa Selic - que remunera os depósitos a prazo - não acompanhada pela redução equivalente nos juros de empréstimos.

\section{Gráfico 4 - Spread relativo}

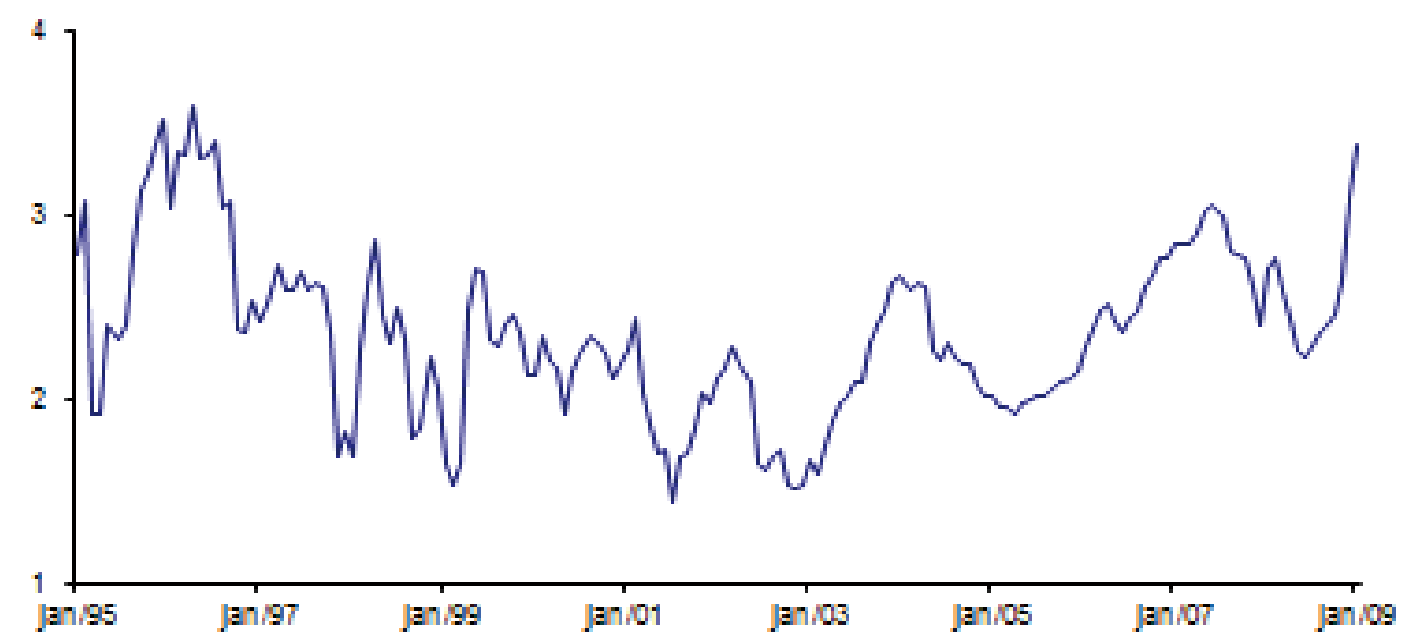

Fonte: Elaboração própria.

A nova variável dependente mostrou-se estacionária para o nível de significância de 5\%. Na estimação com as variáveis estacionárias, cujos resultados constam da Tabela 7, além das variáveis com significância, conforme exercícios anteriores, o SMI apareceu como determinante na formação do spread bancário 
em nível de significância de 5\%. Observe-se que na estimação do spread pelo diferencial de taxas, o SMI mostrou-se relevante em nível de significância de 10\%.

Tabela 7 - Estimação do spread (definição alternativa)

\begin{tabular}{ccccc}
\hline Variable & Coefficient & Std. Error & t-Statistic & Prob \\
\hline D(COMPULS) & $-0,00056$ & 0,00255 & $-0,21919$ & 0,82680 \\
DESP_ADM & $-0,92511$ & 0,50702 & $-1,82463$ & 0,07000 \\
D(INADIMPL) & 0,17257 & 0,06700 & 2,57570 & 0,01090 \\
IOF_OP & 13,29732 & 4,47709 & 2,97008 & 0,00340 \\
IPCA & $-0,07405$ & 0,06728 & $-1,10072$ & 0,27270 \\
LNPIM & 0,40054 & 0,47815 & 0,83769 & 0,40350 \\
D(RC3) & $-0,00516$ & 0,03687 & $-0,13995$ & 0,88890 \\
SELIC & $-0,03109$ & 0,00436 & $-7,13844$ & 0,00000 \\
D(RSKSBR) & $-0,00052$ & 0,00029 & $-1,79954$ & 0,07390 \\
VOL_SELIC & 0,09529 & 0,01240 & 7,68463 & 0,00000 \\
SCR & $-0,09452$ & 0,19080 & $-0,49536$ & 0,62100 \\
SMI & 0,40515 & 0,19625 & 2,06443 & 0,04060 \\
C & 0,96805 & 2,25098 & 0,43006 & 0,66770 \\
R-squared & 0.529857 F-statistic & & 14.74506 \\
Durbin-Watson stat & 0.567649 Prob(F-statistic) & & 0.000000 \\
\hline
\end{tabular}

Fonte: EViews 6.0.

Considerando a existência de autocorrelação dos resíduos, o modelo foi rodado com o estimador de NW. Conforme Tabela 8, a exemplo dos exercícios anteriores, as variáveis inadimplência, IOF, Selic e volatilidade da Selic mostraram-se relevantes na determinação do spread bancário.

Tabela 8 - Estimação do spread (definição alternative e correção NW)

\begin{tabular}{ccccc}
\hline Variable & Coefficient & Std. Error & t-Statistic & Prob \\
\hline D(COMPULS) & $-0,00056$ & 0,00255 & $-0,21919$ & 0,82680 \\
DESP_ADM & $-0,92511$ & 0,50702 & $-1,82463$ & 0,07000 \\
D(INADIMPL) & 0,17257 & 0,06700 & 2,57570 & 0,01090 \\
IOF_OP & 13,29732 & 4,47709 & 2,97008 & 0,00340 \\
IPCA & $-0,07405$ & 0,06728 & $-1,10072$ & 0,27270 \\
LNPIM & 0,40054 & 0,47815 & 0,83769 & 0,40350 \\
\hline
\end{tabular}




\begin{tabular}{ccccc} 
(conclusão) & \multicolumn{5}{c}{} \\
\hline D(RC3) & $-0,00516$ & 0,03687 & $-0,13995$ & 0,88890 \\
SELIC & $-0,03109$ & 0,00436 & $-7,13844$ & 0,00000 \\
D(RSKSBR) & $-0,00052$ & 0,00029 & $-1,79954$ & 0,07390 \\
VOL_SELIC & 0,09529 & 0,01240 & 7,68463 & 0,00000 \\
SCR & $-0,09452$ & 0,19080 & $-0,49536$ & 0,62100 \\
SMI & 0,40515 & 0,19625 & 2,06443 & 0,04060 \\
C & 0,96805 & 2,25098 & 0,43006 & 0,66770 \\
R-squared & 0.529857 F-statistic & & 14.74506 \\
Durbin-Watson stat & 0.567649 Prob(F-statistic) & & 0.000000 \\
\hline
\end{tabular}

Fonte: EViews 6.0.

À primeira vista, destacou-se o sinal estimado para o coeficiente da Selic. A esse respeito, cabe lembrar que se está trabalhando com o spread percentual. Dessa forma, o coeficiente revelou que há umrepasse do aumento da Selic para o spread, mas que ele é menos do que proporcional. Assim, por exemplo, suponha uma relação inicial igual a 2, refletindo taxa de empréstimo de $30 \%$ e taxa de depósito de $10 \%$. Se a Selic é ampliada de $10 \%$ para $11 \%$, a relação reduzir-se-á para 1,97 - considerando o coeficiente de 0,03 negativo. Isso porque a taxa de depósito será ampliada proporcionalmente, mas a taxa de empréstimo passará de 30\% para 32,67\%. Haverá ainda uma expansão do spread absoluto que, no exemplo acima, passaria de 20 p.p. para 21,67 p.p.

Duas das variáveis explicativas tiveram seus resultados alterados quando considerada a medida relativizada da margem líquida de juros. A produção industrial, que era significante na estimação com correção de NW, passou a ser irrelevante nessa estimação. Por sua vez, surgiu como relevante na determinação do spread bancário, o spread soberano.

De acordo com esse procedimento, a dummy para o SMI e outras cinco variáveis explicaram $52,99 \%$ do spread bancário no período examinado. Essa inferência, consoante Gráfico 5, representou um ajuste pior, relativamente à medida do spread absoluto. 

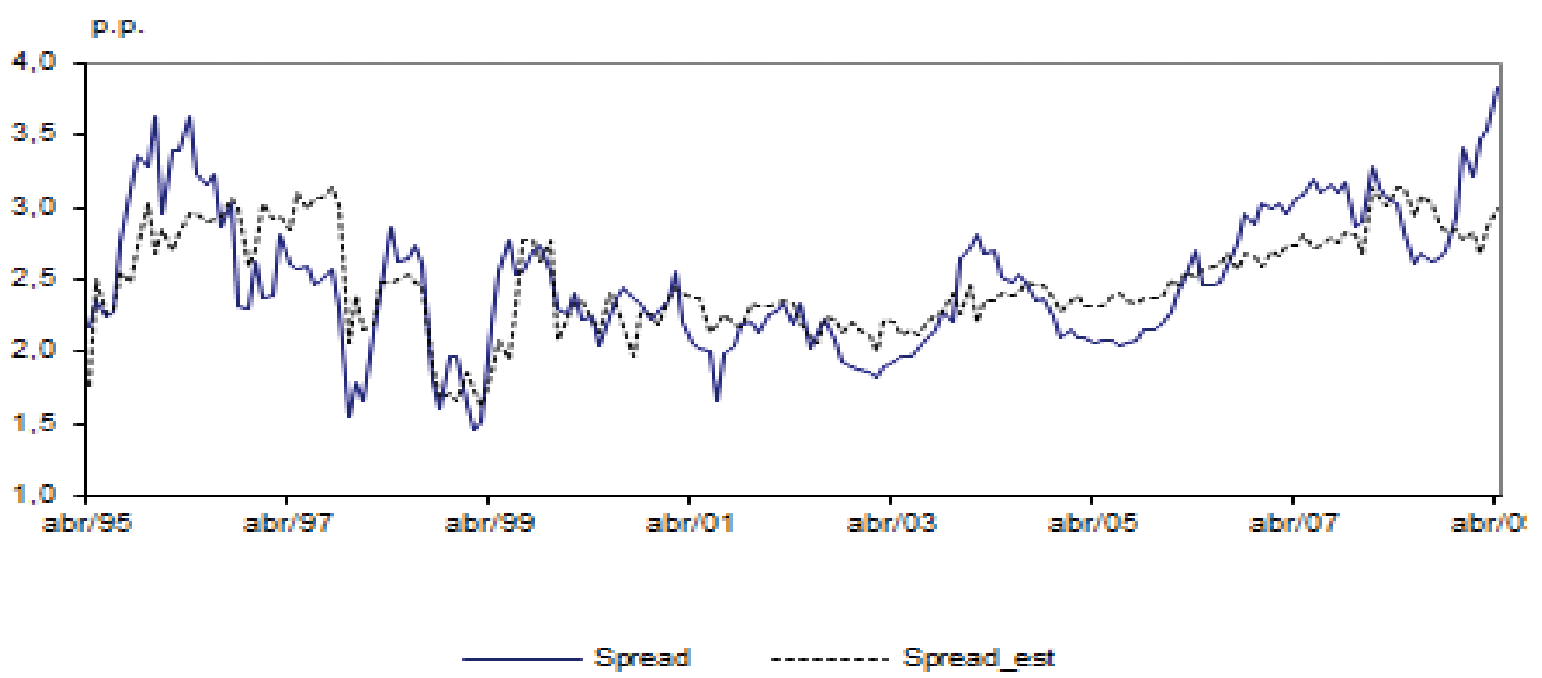

Fonte: Elaboração própria (Spread) e EViews 6.0 (Spread_est).

Por fim, repetiu-se o MCE para a definição alternativa do spread bancário. De acordo com o primeiro procedimento - estimação com as variáveis em nível -, influenciaram o spread a inadimplência, a Selic, a volatilidade da Selic e, adicionalmente, o market share do banco.

Utilizando o resíduo da estimação com as variáveis em nível, procedeu-se à estimação em primeira diferença. Pelo que se denota da saída do Eviews 6.0, esse procedimento excluiu a variável inadimplência e incluiu o risco soberano como determinante do spread bancário, consoante medição relativizada. Os resultados encontram-se na Tabela 9.

Tabela 9 - Estimação do spread (definição alternativa e MCE)

\begin{tabular}{ccccc}
\hline Variable & Coefficient & Std. Error & t-Statistic & Prob. \\
\hline D(COMPULS) & $-0,00145$ & 0,001514 & $-0,09579$ & 0,9238 \\
D(DESP_ADM) & 0,219734 & 0,244684 & 0,898033 & 0,3706 \\
D(INADIMPL) & 0,067992 & 0,038048 & 1,787038 & 0,0759 \\
D(IOF_OP) & 7,635939 & 2,518783 & 3,031598 & 0,0029 \\
D(IPCA) & $-0,032503$ & 0,039264 & $-0,827813$ & 0,4090 \\
D(LNPIM) & $-0,005021$ & 0,649187 & $-0,007734$ & 0,9938 \\
D(RC3) & 0,030398 & 0,020424 & 1,488339 & 0,1387 \\
D(RSKSBR) & $-0,000361$ & 0,000162 & $-2,23339$ & 0,0270 \\
D(SELIC) & $-0,021108$ & 0,004102 & $-5,145608$ & 0,0000 \\
D(VOL_SELIC) & 0,095692 & 0,047894 & 1,998009 & 0,0475 \\
D(SCR) & 0,041331 & 0,211811 & 0,195129 & 0,8455 \\
\hline
\end{tabular}

(continua...) 


\begin{tabular}{ccccc}
\hline D(SMI) & $-0,069577$ & 0,201044 & $-0,346077$ & 0,7298 \\
RESID02(-1) & $-0,298027$ & 0,067405 & $-4,421448$ & 0,0000 \\
C & 0,013296 & 0,016278 & 0,816812 & 0,4153 \\
R-squared & 0,293523 & F-statistic & 4,95373 \\
Durbin-Watson stat & 1,913391 & Prob(F-statistic) & 0,00000 \\
\hline
\end{tabular}

Fonte: EViews 6.0.

A equação em diferença de estimação do modelo de correção de erros, com as variáveis determinantes do spread bancário, para um p-value de $5 \%$, considerou além do resíduo da equação em nível, as variáveis IOF, o risco soberano, a Selic e a volatilidade da Selic. A esse nível de significância, a inadimplência de operações de crédito perde capacidade explicativa sobre a variável dependente. Note-se, contudo, que, dentre todos os exercícios realizados, a cointegração do spread percentual foi a que mais distanciou o spread observado do estimado pelo modelo, conforme mostra o Gráfico 6.

Gráfico 6 - Variação do spread relativo observado e estimado, cointegração das séries

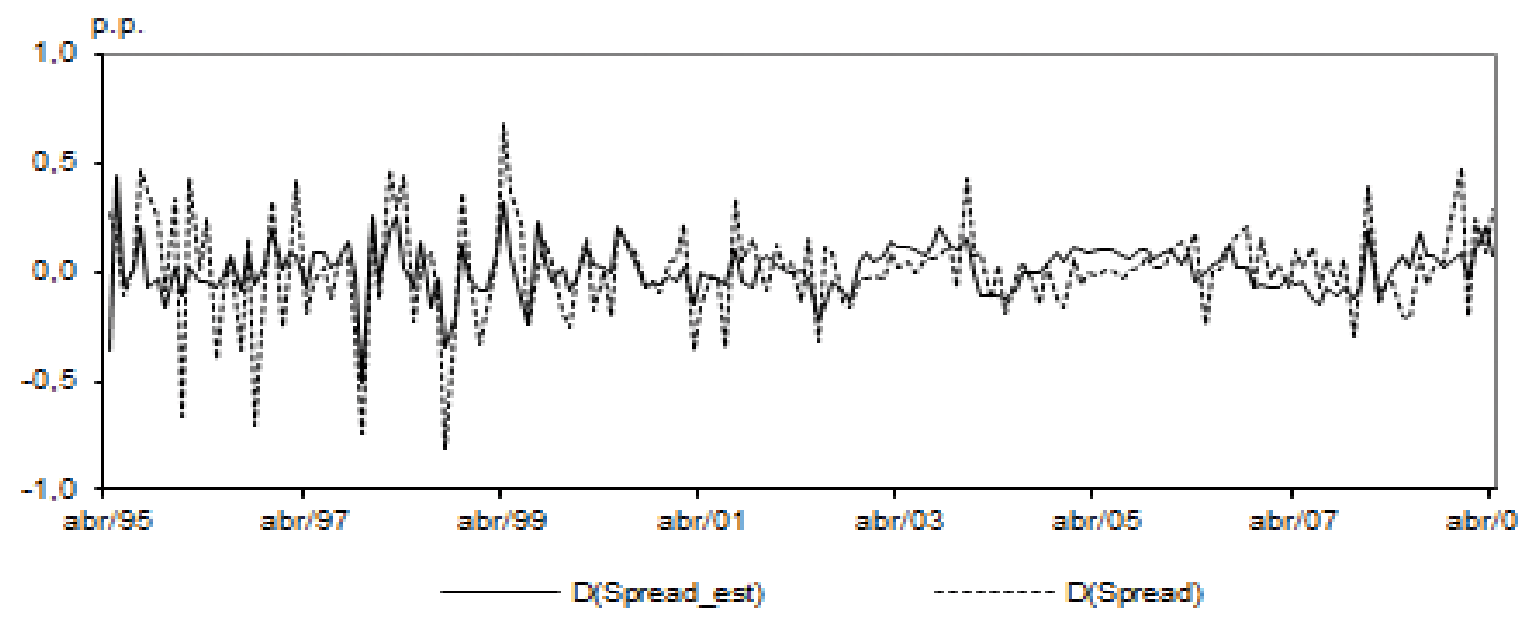

Fonte: EViews 6.0.

A síntese dos resultados obtidos nos exercícios de estimação do spread bancário pela diferença entre taxas de aplicação e de captação e pela relativização das referidas taxas consta do Quadro 1. Os métodos consideraram o procedimento de NW e MCE. 
Quadro 1- Coeficiente das variáveis na determinação do spread bancário

\begin{tabular}{|c|c|c|c|c|}
\hline \multirow{2}{*}{ Variável } & \multicolumn{2}{|c|}{ Spread em pontos percentuais } & \multicolumn{2}{|c|}{ Spread relativo } \\
\hline & NW & MCE & NW & MCE \\
\hline \multirow{2}{*}{ Compulsório } & 0,02 & 0,01 & $-0,0005$ & $-0,0001$ \\
\hline & $(0,43)$ & $(0,29)$ & $(-0,22)$ & $(-0,10)$ \\
\hline \multirow{2}{*}{$\begin{array}{l}\text { Despesas admi- } \\
\text { nistrativas }\end{array}$} & 15,22 & 3,93 & $-0,92$ & 0,22 \\
\hline & $(1,10)$ & $(1,11)$ & $(-0,98)$ & $(0,90)$ \\
\hline \multirow{2}{*}{ Inadimplência } & 5,72 & 1,44 & 0,17 & 0,07 \\
\hline & $(2,32)$ & $(2,57)$ & $(2,19)$ & $(1,79)$ \\
\hline \multirow{2}{*}{ IOF } & 423,23 & 130,94 & 13,30 & 7,64 \\
\hline & $(2,65)$ & $(3,63)$ & $(2,19)$ & $(1,79)$ \\
\hline \multirow{2}{*}{ IPCA } & 1,51 & $-0,32$ & $-0,07$ & $-0,03$ \\
\hline & $(0,85)$ & $(-0,57)$ & $(-0,88)$ & $(-0,82)$ \\
\hline \multirow{2}{*}{ PIM } & $-25,70$ & $-17,69$ & 0,40 & $-0,05$ \\
\hline & $(-2,41)$ & $(-1,90)$ & $(0,57)$ & $(-0,008)$ \\
\hline \multirow{2}{*}{ Market Share } & $-0,79$ & 0,28 & $-0,005$ & 0,03 \\
\hline & $(-0,86)$ & $(0,95)$ & $(-1,99)$ & $(1,49)$ \\
\hline \multirow{2}{*}{ Risco soberano } & 0,001 & 0,0003 & $-0,0005$ & 0,03 \\
\hline & $(0,22)$ & $(0,15)$ & $(-1,99)$ & $(1,49)$ \\
\hline \multirow{2}{*}{ Selic } & 1,02 & 0,32 & $-0,03$ & $-0,02$ \\
\hline & $(5,83)$ & $(6,10)$ & $(-4,74)$ & $(-5,15)$ \\
\hline \multirow{2}{*}{$\begin{array}{l}\text { Volatilidade da } \\
\text { Selic }\end{array}$} & 2,56 & 2,67 & 0,09 & 0,1 \\
\hline & $(5,29)$ & $(3,83)$ & $(4,31)$ & $(2,00)$ \\
\hline \multirow{2}{*}{ Dummy p/ SCR } & 6,28 & $-0,87$ & $-0,09$ & 0,04 \\
\hline & $(1,27)$ & $(-0,29)$ & $(-0,52)$ & $(0,20)$ \\
\hline \multirow{2}{*}{ Dummy p/ SMI } & 7,73 & $-0,68$ & 0,40 & $-0,06$ \\
\hline & $(1,80)$ & $(-0,24)$ & $(2,01)$ & $(-0,35)$ \\
\hline $\mathrm{R}^{2}$ & 0,925684 & 0,421335 & 0,529857 & 0,293523 \\
\hline Estatística-F & 162,9665 & 8,6814 & 14,74506 & 4,95373 \\
\hline
\end{tabular}

Fonte: Elaboração própria.

Notas: Estatística-t entre parênteses; Procedimento de Newey-West e modelo de correção de erros. 


\section{Considerações Finais}

O artigo investigou os determinantes do spread bancário no Brasil, a partir de desenvolvimentos fundamentados no modelo teórico de Ho e Saunders (1981), que possibilita, além das variáveis da firma bancária, a inclusão de fatores macroeconômicos na explicação da margem líquida de juros. Uma vez que não se objetivou a discriminação do spread puro, tal qual proposto por esses autores, optou-se pela estimação em um "único estágio", como realizado por Maudos e Guevara (2004).

As inferências consideraram dois diferentes modelos e métodos, além de trabalhar com duas definições para a variável dependente. Nada obstante isso, os resultados foram razoavelmente similares, evidenciando a sua robustez. Particularmente a regressão com variáveis estacionárias e correção por NW evidenciou grande capacidade explicativa. O coeficiente de determinação encontrado permite concluir que as variáveis independentes inseridas no modelo estimaram com sucesso o spread no período da amostra.

Dentre as variáveis analisadas nos exercícios econométricos, IOF, Selic e volatilidade da Selic apareceram como determinantes significativos em todos os procedimentos elaborados. Considerando que a evolução dessas variáveis é decorrente das políticas tributária e monetária, é plausível supor que decisões de política econômica que afetam tais variáveis têm impacto sobre o custo do crédito.

Relativamente ao risco de crédito, que evidenciou capacidade explicativa na maior parte das inferências, sua redução - em ambiente de estabilidade econômica - deve atrelar-se à eficiência na seleção do crédito e das garantias adequadas. Adicionalmente, ele dependerá do comportamento da firma bancária, no que diz respeito à sua exposição ao risco. Ao longo do período examinado, houve redução no default das operações de crédito, com impacto positivo sobre a diminuição do spread.

A acomodação de custos diretos e indiretos no spread bancário - isto é, inadimplência e IOF - é essencialmente decorrente da composição e definição da variável. De outra parte, o fato das despesas administrativas não influenciarem a margem líquida deve decorrer da relação insignificante e decrescente no tempo dessa variável, relativamente ao ativo circulante e realizável a curto prazo. Outra possibilidade é a de que a variação das despesas administrativas provoque movimento nos preços dos serviços bancários, itens cuja receita tem evoluído significativamente.

Um forte indício para a Selic ser determinante do spread bancário, apesar de estar considerada na remuneração dos depósitos, é que essa taxa refletiria o custo de oportunidade de aplicação dos recursos dos bancos. Isto é, o que expli- 
caria o fato de a Selic ser determinante, visto que esta taxa é, grosso modo, o custo de captação dos recursos? Conforme Paula e Pires (2007, p. 177),

[u]ma possível explicação para isso é que, dada a existência de títulos indexados à Selic na carteira dos bancos, que é uma alternativa de aplicação rentável e líquida, o custo de oportunidade de emprestar por parte dos bancos tende a aumentar, passando a incorporar um elevado prêmio de risco em seus empréstimos.

A significância da volatilidade da taxa básica de juros havia sido referenciada no artigo seminal de Ho e Saunders (1981), para quem o spread puro é fortemente dependente de mudanças nessa variável, afirmação que foi reforçada pelos resultados inferidos em todos os exercícios realizados neste artigo.

Por seu turno, a aplicação de dummies de tempo para o SMI e SCR não surtiram os efeitos esperados nas estimações do spread bancário. O primeiro desses sistemas não agregou capacidade explicativa nas estimações. De fato, a inclusão da variável inadimplência parece ter capturado todo o efeito sobre o spread bancário.

Quanto ao SMI, sua influência sobre o nível de preços, Selic e volatilidade da Selic igualmente seriam manifestados diretamente por cada uma dessas variáveis. Enquanto o IPCA não assinalou qualquer efeito sobre o spread bancário, as outras duas apresentaram significância nos diferentes modelos e métodos. De fato, a estimação com a exclusão dessas variáveis independentes fez com que o resultado para o SMI fosse fortemente significativo.

Embora o SMI possa provocar, em princípio, maior nível e volatilidade da Selic, sua adoção no Brasil coincidiu com período de redução no patamar e na variância da taxa básica de juros de curto prazo. Com isso, houve um efeito positivo sobre a redução do spread bancário, embora não se tenha observado convergência dessa taxa aos níveis praticados internacionalmente.

\section{Referências}

AFANASIEFF, T. S.; LHACER, P. M. V.; NAKANE, M. I. The Determinant of Bank Interest Spread in Brazil. Brasília: Banco Central do Brasil, 2002.

BANCO CENTRAL DO BRASIL. Séries Temporais. 2009. Disponível em: <www.bcb.gov.br>. Acesso em: 21 nov. 2009.

BIGNOTTO, F. G.; RODRIGUES, E. A. S. Fatores de risco e o spread bancário no Brasil. In: Juros e Spread Bancário no Brasil. Brasília: Banco Central do Brasil, 2006.

BROCK, P. L.; SUAREZ, L. R. Understanding the behavior of bank spreads in Latin America. Journal of Development Economics, v. 63, p. 113-34, 2001. 
CUNHA, M. S. Raiz unitária e co-integração: três aplicações. Brasília: UnB, 2002. (Textos didáticos, n. 40).

DEMIRGUÇ-KUNT, A.; HUIZINGA, H. Determinants of commercial bank interest margins and profitability: some international evidence. The World Bank Economic Review, v. 13, n. 2, p. 379-408, 1999.

GUJARATI, D. Econometria Básica. Rio de Janeiro: Campus, 2006.

HARRIS, R.I.D. Using Cointegration Analysis in econometric modeling. London: Prentice Hall, 1995.

HO, T.; SAUNDERS, A. The determinants of bank interest margins: theory and evidence. The Journal of Financial and Quantitative Analysis, v. 16, n. 4, p. 581-600, 1981.

INSTITUTO BRASILEIRO DE GEOGRAFIA E ESTATÍSTICA. Sistema IBGE de recuperação Automática SIDRA. 2010. Disponível em: <http://www.sidra.ibge.gov.br/bda/default.asp?t $=$

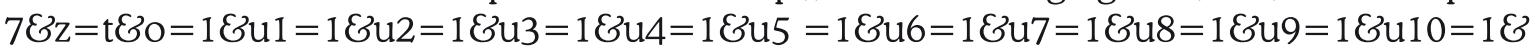
$\mathrm{u} 11=1 \mathcal{E} \mathrm{u} 12=3 \mathcal{E} \mathrm{u} 13=1 \mathcal{E} \mathrm{u} 14=26674 \mathcal{E} \mathrm{u} 15=1 \mathcal{E} \mathrm{u} 16=>$. Acesso em: 5 jan. 2010.

INSTITUTO PESQUISA ECONÔMICA APLICADA. IPEADATA. 2010. Disponível em: $<$ : http://ipeadata.gov.br >. Acesso em: 5 jan. 2010.

LERNER, E. M. The determinants of banks interest margins: Theory and empirical evidence. Journal of Financial and Quantitative Analysis, v. 16, n. 4, p. 601-602, 1981.

MADDALA, G. S. Introdução à Econometria. Rio de Janeiro: LTC, 2003.

MAUDOS, J.; GUEVARA, J. F. Factors explaining the interest margin in the banking sectors of the European Union. Journal of Banking and Finance, v. 28, n. 9, p. 2259-81, 2004.

NEWEY, W.; WEST, K. Hypothesis Testing with Efficient Method of Moments Estimation. International Economic Review, v. 28, n.3, p. 777-788, 1987.

OREIRO, J. L. et al. Determinantes macroeconômicos do spread bancário no Brasil: teoria e evidência recente. Economia Aplicada, v. 10, n. 4, p. 609-34, 2006.

PAULA, L. F.; PIRES, M. C. C. Determinantes macroeconômicos do spread bancário: uma análise preliminar para economias emergentes. In: PAULA, L. F.; OREIRO, J. L. (Org.). Sistema Financeiro: uma análise do setor bancário brasileiro. Rio de Janeiro: Campus, 2007.

SAUNDERS, A.; SCHUMACHER, L. The determinants of bank interest rate margins: an international study. Journal of International Money and Finance, v. 19, p. 813-32, 2000.

Recebido em: 07/03/2012.

Aceito em: 23/06/2012. 